\title{
Brugada Syndrome or Phenocopy? Diagnostic Challenge in Patients with Pectus Excavatum
}

\section{Síndrome de Brugada ou Fenocópia? Desafio Diagnóstico em Paciente com Pectus Excavatum}

Kárila Scarduelli Luciano ${ }^{1, *}$, Larissa Freitas Nunes Goldoni ${ }^{1}$, Rafaela Louise Sales ${ }^{1}$, Rafael de March Ronsoni ${ }^{1}$

Luciano KS (D) https://orcid.org/0000-0002-5210-8414

Goldoni LFN (D) https://orcid.org/0000-0003-4340-0349

Sales RL (D) https://orcid.org/0000-0002-5725-279X

Ronsoni RM (D) https://orcid.org/0000-0001-7135-9844

\begin{abstract}
Brugada syndrome is an autosomal dominant heart disease caused by dysfunctions in the ionic channels, whose carriers present a classic electrocardiographic pattern and predisposition to malignant ventricular arrhythmias. The electrocardiogram alterations may be dynamic, spontaneous, or induced by sodium channel blocking drugs (ajmaline, procainamide, etc.). However, electrocardiographic findings that diagnose Brugada syndrome may occur even in the absence of congenital dysfunction of ionic channels, characterizing "Brugada phenocopy", therefore the exclusion of secondary causes is fundamental for the correct diagnosis of channelopathy.
\end{abstract}

KEYWORDS: Brugada syndrome; Channelopathies; Sudden cardiac death.

\section{RESUMO}

A Síndrome de Brugada é uma doença cardíaca autossômica dominante causada por disfunções nos canais iônicos, cujos portadores apresentam padrão eletrocardiográfico clássico e predisposição a arritmias ventriculares malignas. As alterações do eletrocardiograma podem ser dinâmicas, espontâneas ou induzidas por drogas bloqueadoras dos canais de sódio (ajmalina, procainamida, etc.). No entanto, os achados eletrocardiográficos que diagnosticam Síndrome de Brugada podem ocorrer mesmo na ausência de disfunção congênita dos canais iônicos, caracterizando "fenocópia de Brugada", portanto a exclusão de causas secundárias é fundamental para o correto diagnóstico da canalopatia.

PALAVRAS-CHAVE: Síndrome de Brugada; Canalopatias; Morte súbita cardíaca.

1. Hospital Regional Hans Dieter Schmidt - Setor de Cardiologia - Joinville (SC) - Brazil

*Correspondence author: karilasl@gmail.com

Received: 25 Aug 2019 | Accepted: 04 Oct 2019

Section Editor: Cristiano de Oliveira Dietrich 


\section{INTRODUCTION}

Brugada syndrome (BS) is an autosomal dominant disease caused by dysfunctions in the cardiac ionic channels. It presents a diagnostic electrocardiographic pattern called type 1 , determined by the elevation of the ST segment $>2 \mathrm{~mm}$ in at least one right precordial lead (in the second, third, or fourth intercostal space), followed by a descending concave or rectilinear ST segment. The descending ST segment crosses the isoelectric line and is followed by a negative and symmetrical $\mathrm{T}$ wave ${ }^{1}$.

The type 1 pattern may occur spontaneously; in this case, generally dynamic, or induced by antiarrhythmic sodium channel blockers. Although this pattern is fundamental for the diagnosis, it can be found in the absence of the genetic syndrome in some specific conditions such as pectus excavatum, characterizing the Brugada phenocopy. Therefore, the exclusion of secondary causes is fundamental for the correct diagnosis of channelopathy ${ }^{1,2}$.

\section{CASE DESCRIPTION}

A male, 70-year-old patient, 50 pack-year smoker, with systemic arterial hypertension and ambulatory monitoring using enalapril $20 \mathrm{mg} /$ day. Asymptomatic and without a personal history of syncope or nocturnal agonal respiration. Family history of a father with sudden death at the age of 42 at rest, without cause of death report.

Ambulatory electrocardiogram in sinus rhythm and V2 with a saddle-back aspect, compatible with the Brugada type 2 pattern (Fig. 1a). During a physical examination, the presence of pectus excavatum was observed (Fig. 2b).

He underwent transthoracic echocardiography with a moderate increase in the left atrium, grade I diastolic dysfunction of the left ventricular (LV) with preserved systolic functions of the left and right ventricles (RV) and no evidence of RV compression. Spirometry with the moderate obstructive ventilatory disorder without response to bronchodilator, compatible with the history of smoking. Thoracic tomography (Fig. 2a) with a standard Haller index, estimated at 2.45.

The patient was in programming for a provocative test with a sodium channel blocker. However, in serial ambulatory electrocardiography in sequential consultations, he presented a dynamic pattern compatible with type 1 (Fig. 1b). No QRS fragmentation was observed.

The dynamic electrocardiographic pattern evolving spontaneously to type 1 and the family history of sudden death consolidated the diagnosis of BS. Due to the advanced age and absence of symptoms in previous phases of the syndrome, known to be more arrhythmogenic, allied to the lack of QRS fragmentation during the type 1 pattern, we opted only for behavioral orientation and clinical follow-up at this time.

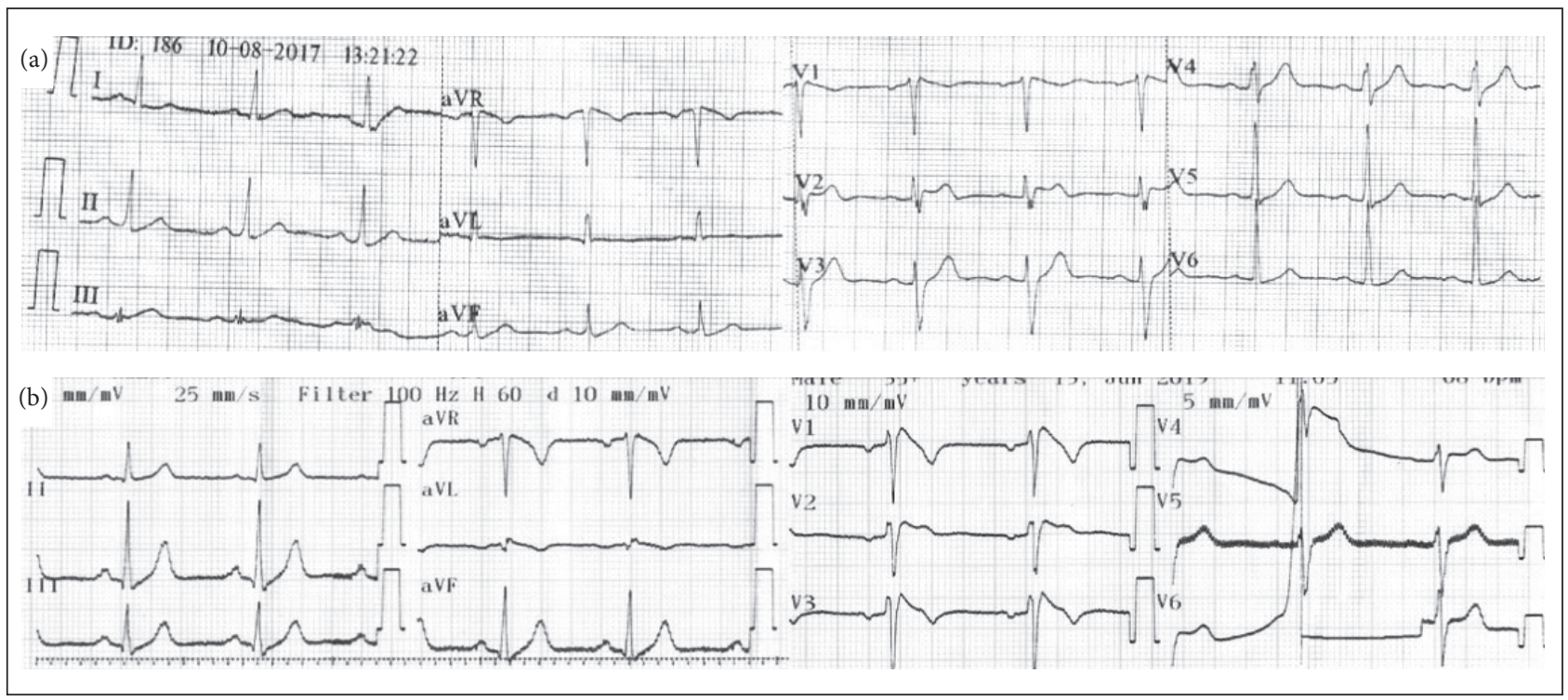

Figure 1. (a) Standard electrocardiogram Brugada type 2 and (b) Brugada type 1. 


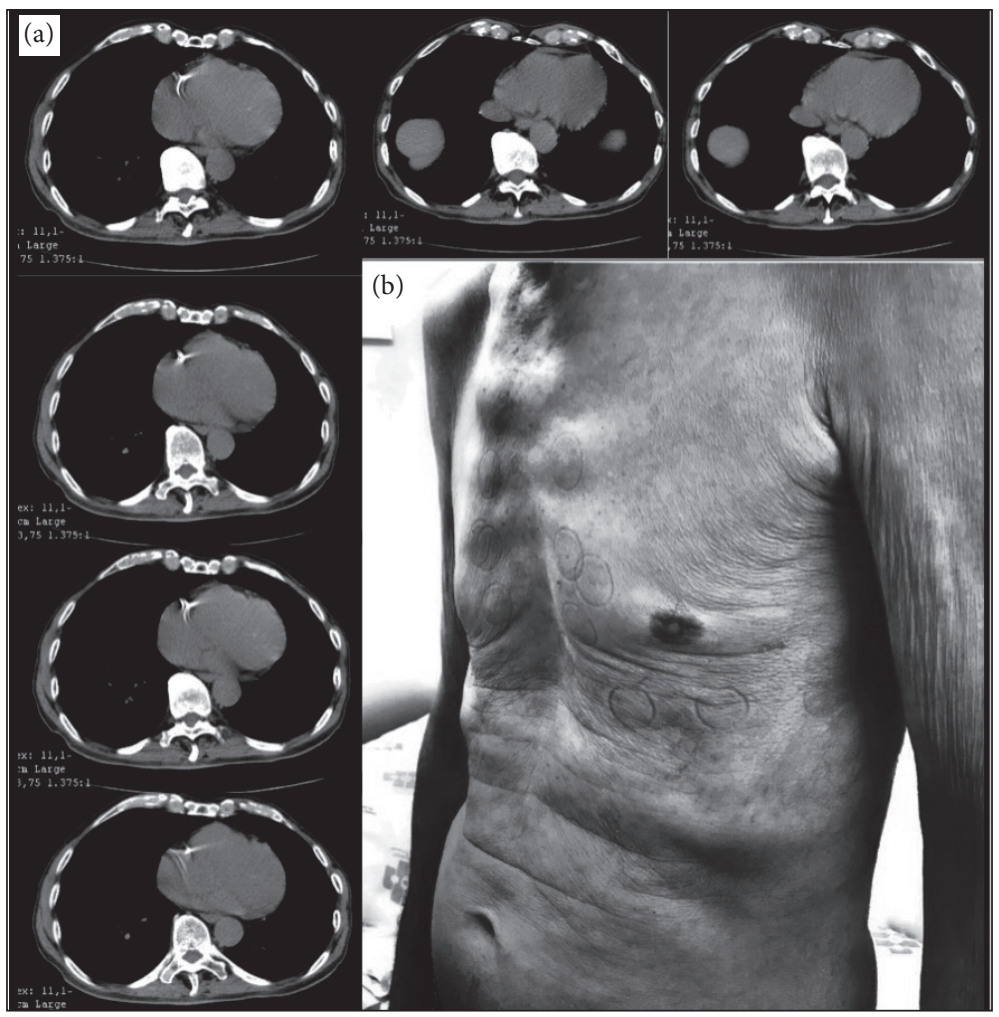

Figure 2. (a) CT scan and (b) physical examination with pectus excavatum.

\section{DISCUSSION}

Electrocardiographic findings of BS, type 1 or type 2, can be found even in the absence of congenital dysfunction of ionic channels. These cases are known as Brugada phenocopy, and most are related to metabolic or hydro electrolytic imbalances, ischemia, embolism, or mechanical compression of the $\mathrm{RV}^{1,3}$.

The definition of phenocopy and exclusion of the genetic syndrome is often a challenge in patients with pectus excavatum, who may present type 1 or type 2 pattern due to mechanical compression of the $\mathrm{RV}^{3,5}$.

There is no electrocardiographic marker to distinguish the Brugada phenocopy from the genetic syndrome. Recently, a four-step approach was suggested to identify the possibility of treating phenocopy in patients with the typical electrocardiographic pattern of BS in the presence of a clinical condition that could knowingly influence the electrocardiographic phenotype ${ }^{4}$.

This approach consists of 1 ) identifying Brugada Syndrome type 1 or 2 electrocardiographic pattern; 2 ) determining whether there is a low probability of pre-test of BS, especially related to patient symptoms and family history; 3 ) performing provocative pharmacological testing with a sodium channel blocker; 4) performing genetic tests (this criterion is not mandatory) ${ }^{4}$.

In general, Brugada phenocopy of pectus excavatum patients are asymptomatic, have no family history of sudden death and complementary examinations show signs of extrinsic compression of the RV free wall, objectively in imaging examinations such as echocardiography evaluating the RV dynamics or subjectively through additional examinations that indicate the severity of pectus excavatum.

Thoracic tomography is useful in assessing the degree of sternal depression and thoracic deformation, as well as cardiac involvement. The Haller index estimates the severity of pectus excavatum, where values $>3.25$ denote severe compression. In moderate to severe cases, spirometry may show restrictive ventilatory disorder due to a decrease in intrathoracic volume with a consequent reduction of lung volumes caused by compression of pectus excavatum ${ }^{3,5,6}$.

Also, patients with mechanical compression Brugada phenocopy who remain only with type 2 electrocardiographic patterns do not evolve to type 1 spontaneously or after using antiarrhythmic sodium channel blockers ${ }^{1,5}$. 
In our patient's case, due to his advanced age and the fact that he has never presented clinical manifestations of BS, along with physical examination with pectus excavatum, the Brugada phenocopy was considered the first diagnostic hypothesis. However, the complementary exams showed no RV impairment or even severity of pectus excavatum that would justify the electrocardiographic alteration initially recorded as type 2 Brugada pattern.

The next step in the diagnostic elucidation would be to perform a provocative test with a sodium channel blocker to evaluate a change from type 2 to type 1 pattern in the diagnosis of BS. However, in the spontaneous and dynamic ambulatory monitoring, the patient presented a type 1 pattern, consolidating the diagnosis of a genetic syndrome.

Some variables may be implicated in worse prognosis and used in risk stratification and primary prevention of patients with BS: spontaneous type 1 pattern, history of unexplained syncope, presence of QRS fragmentation, and electrophysiological study with a ventricular refractory period less than $200 \mathrm{~ms}^{7}$.

It is described that patients over 60 years of age with a diagnosis of BS present a better prognosis, both to primary events and the occurrence of ICD shocks when it is indicated for secondary prophylaxis for events in previous phases. This better evolution seems to be related to the decrease of testosterone on Ito channels, which may contribute to the low incidence of ventricular fibrillation in senior patients with $\mathrm{BS}^{8,9,10}$.

The late diagnosis at 70 years of age, the absence of clinical symptoms in more arrhythmogenic BS early stages, the lack of QRS fragmentation, and the ephemeral appearance of the spontaneous type 1 pattern, meant that only behavioral orientation and clinical monitoring were performed in our patient at this time. However, the diagnosis of BS in the seniors should not be neglected, mainly due to the importance of family screening and clinical impact on the family of these probands.

\section{AUTHORS' CONTRIBUTION}

Conceptualization, Luciano KS; Methodology, Luciano KS, Ronsoni RM; Writing - First version, Luciano KS, Ronsoni RM, Goldoni LFN, Sales RL; Writing - Review \& Editing, Luciano KS, Ronsoni RM; Funding Aquisition, Goldoni LFN, Sales RL; Resources, Goldoni LFN, Sales RL; Supervision, Ronsoni RM.

\section{REFERENCES}

1. Oliveira-Neto NR, Oliveira WS, Mastrocola F, Sacilotto L. Brugada phenocopy: Mechanisms, diagnosis, and implications. J Eletrocardiol. 2019;55:45-50. https://doi. $\operatorname{org} / 10.1016 /$ j.jelectrocard.2019.04.017

2. Dendramis G. Brugada syndrome and Brugada phenocopy. The importance of a differential diagnosis. Int J Cardiol. 2016;210:25-7. https://doi.org/10.1016/j.jjcard.2016.02.097

3. Awad SF, Barbosa-Barros R, Belem LS, Cavalcante CP, Riera AR, Garcia-Niebla J, et al. Brugada phenocopy in a patient with pectus excavatum: systematic review of the ECG manifestations associated with pectus excavatum. Ann Noninvasive Electrocardiol. 2013;18(5):415-20. https://doi. org/10.1111/anec.12082

4. Gottschalk BH, Anselm DD, Baranchuk A, Xu G. Brugada Phenocopy international registry and online educational portal [Internet]. 2014 [cited 2019 Ago 24]. Available at: http://www.brugadaphenocopy.com

5. Marchetti M, Sierecki M, Oriot D, Ghazali A. Brugada-type ECG associated with pectus excavatum. Images Paediatr Cardiol. 2015;17(3):1-2.

6. Abid I, Ewais MM, Marranca J, Jaroszewski DE. Pectus excavatum: A review of diagnosis and current treatment options. J Am Osteopath Assoc. 2017;117(2):106-13. https:// doi.org/10.7556/jaoa.2017.021

7. Priori SG, Gasparini M, Napolitano C, Della BP, Ottonelli AG, Sassone B, et al. Risk stratification in Brugada syndrome: results of the PRELUDE (PRogrammed ELectrical stimUlation preDictive valuE) registry. J Am Coll Cardiol. 2012;59:37-45. https://doi.org/10.1016/j.jacc.2011.08.064

8. Kitamura T, Fukamizu S, Kawamura I, Hojo R, Aoyama Y, Nishizaki $M$, et al. Clinical characteristics and long-term prognosis of senior patients with Brugada syndrome. J Am Coll Cardiol. 2017;3(1):57-67. https://doi.org/10.1016/j.jacep.2016.04.004

9. Conte G, Asmundis C, Sieira J, Levinstein M, Chierchia GB, Giovanni G, et al. Clinical characteristics, management, and prognosis of elderly patients with Brugada syndrome. J Cardiovasc Electrophysiol. 2014;25(5):514-19. https://doi. org/10.1111/jce.12359

10. Kamakura T, Wada M, Nakajima I, Ishibashi K, Miyamoto K, Okamura $\mathrm{H}$, et al. Evaluation of the necessity for cardioverterdefibrillator implantation in elderly patients with Brugada syndrome. Circ Arrhythm Electrophysiol. 2015;8(4):785-91. https://doi.org/10.1161/CIRCEP.114.002705 